\title{
Thyroid hormone and intestinal tumor: a Wnt connection
}

\section{Yun-Bo Shi}

News on: Increased expression of the thyroid hormone nuclear receptor TRal characterizes intestinal tumors with high Wnt activity by Uchuya-Castillo J, et al. Oncotarget. 2018; 9:30979-30996. https://doi.org/10.18632/oncotarget.25741

The mammalian intestine has been well-studied as a model system for adult organ-specific stem cells due to the life-long self-renewal of the intestinal epithelium. In the adult, the stem cells near the bottom of the intestinal crypts proliferate and their offspring differentiate into different epithelial cells as they migrate along the crypt-villus axis. The epithelial cells are eventually removed through programmed cell death near the tip of the villus, a process that is conserved in all vertebrates [1-3]. Extensive studies, especially with the use of mouse genetics, have revealed important molecular mechanisms governing intestinal stem cells, including the requirement of the Wnt signaling pathway [1]. Much less is known about the formation of adult intestinal stem cells during vertebrate development. Accumulating evidence indicates that they are formed during the neonatal period in mammals, also known as postembryonic period, when plasma thyroid hormone (T3) levels are high $[2,3]$. A role of T3 in the development and function of adult intestinal stem cells is also supported by several other lines of evidence. First, the T3 levels are altered in patients with intestinal abnormalities and diseases [3]. Second, T3 deficiency or knocking out TR $\alpha$, the predominant TR in mouse intestine, causes intestinal defect, including stem cell proliferation [4]. Finally, human patients with TR $\alpha$ mutations have constipations, suggesting a critical role of TR $\alpha$ in human intestine [5].

Intestinal tumors, particularly, colorectal cancers, affects a large fraction of the human population. These tumors are derived due to dysregulated epithelial cell proliferation. Not surprisingly, the Wnt pathway, which are critical for stem cell development and function [4], are involved in intestinal tumor development and can interact with the $\beta$-catenin/APC pathway, which is a critical player in human colorectal cancer [6]. Given the effect of T3 on intestinal stem cell development and/or function, one may expect that $\mathrm{T} 3$ signaling affect intestinal tumor development. Indeed, TR $\beta$ mutations and changes in TR expression have been reported in intestinal tumors [3]. Furthermore, transgenic overexpression studies have shown that TR $\alpha 1$ enhances tumor development in an APC-mutated mouse model with over-activation of Wnt signaling [7].

A recent study by $M$. Plateroti and her colleagues provides clinical evidence and molecular insights into the synergy between TR $\alpha 1$ and Wnt signaling pathway in intestinal tumor development [8]. Through bioinformatics analysis of a human colon cancer database, the authors discovered that increased TR expression is correlated with high Wnt activity in colorectal cancer samples. Functional studies in $\mathrm{Caco} 2$ cells demonstrated that $\mathrm{TR} \alpha 1$ regulates
Wnt activity to affect colon cancer cell proliferation and migration. By using their intestinal tumor model with overexpressed $\mathrm{TR} \alpha 1$ for transcriptomic analysis, the authors discovered that TR $\alpha 1$ represses the expression of Wnt inhibitors, including Frzb, Sox17 and Wif1. Importantly, bioinformatics analysis of the human colon cancer database showed that these Wnt inhibitors were expressed at lower levels in tumors than in normal tissues and that their expression had an inverted correlation with that of TR $\alpha 1$ in human colorectal cancer patients. These findings not only highlight the importance of increased TR $\alpha 1$ expression in intestinal cancer development and progression but also reveal that Wnt signaling pathway plays a critical role in mediating T3 signaling in intestinal tumorigenesis. They further suggest that like T3 signaling, dysregulation of other factors that participate in the development of adult intestinal stem cells may also contribute to intestinal tumor development and progression.

Yun-Bo Shi: Molecular Morphogenesis, National Institute of Child Health and Human Development, National Institutes of Health, Bethesda, MD, USA

Correspondence to: Yun-Bo Shi, email Shi@helix.nih.gov

Keywords: Thyroid hormone receptor; colorectal cancer; adult intestinal stem cells; $\beta$-catenin/APC pathway; Wnt

Received: June 28, 2018

Published: August 10, 2018

\section{REFERENCES}

1. van der Flier LG, et al. Annu Rev Physiol. 2009; 71:241260 .

2. Ishizuya-Oka A, et al. Cell Biosci. 2011; 1:37.

3. Sun G, et al. Rev Endocr Metab Disord. 2016; 17:559-569.

4. Sirakov M, et al. Cell Mol Life Sci. 2014; 71:2897-2907.

5. Moran C, et al. Best Pract Res Clin Endocrinol Metab. 2015; 29:647-657.

6. Clevers H, et al. Cell. 2012; 149:1192-1205.

7. Kress E, et al. Gastroenterology. 2010; 138:1863-1874.

8. Uchuya-Castillo J, et al. Oncotarget. 2018; 9:30979-30996. https://doi.org/10.18632/oncotarget.25741

Copyright: Shi et al. This is an open-access article distributed under the terms of the Creative Commons Attribution License 3.0 (CC BY 3.0), which permits unrestricted use, distribution, and reproduction in any medium, provided the original author and source are credited. 